\title{
Wilms tumor: a review of current surgical controversies
}

\author{
Karen Milford, Keara DeCotiis, Armando Lorenzo \\ Division of Urology, The Hospital for Sick Children, University of Toronto, Toronto, Ontario, Canada \\ Contributions: (I) Conception and design: All authors; (II) Administrative support: All authors; (III) Provision of study materials or patients: All \\ authors; (IV) Collection and assembly of data: All authors; (V) Data analysis and interpretation: All authors; (VI) Manuscript writing: All authors; (VII) \\ Final approval of manuscript: All authors. \\ Correspondence to: Karen Milford. Division of Urology, The Hospital for Sick Children, 555 University Avenue, Toronto, Ontario, M5G 1X8, Canada. \\ Email: karen.milford@sickkids.ca.
}

\begin{abstract}
Overall survival (OS) for children with Wilms tumor (WT) currently stands at around $90 \%$. This is markedly improved from the survival rates of around $30 \%$ reported in the middle of the last century. This improvement is due to the development of multimodal treatment for this disease, based on the evidence yielded through international collaboration on trials conducted by the Société Internationale d'Oncologie Pédiatrique (SIOP) and the Children's Oncology Group (COG). In this article, we review some of the current surgical controversies surrounding the management of WT.
\end{abstract}

Keywords: Wilms tumor (WT); nephroblastoma; nephron sparing surgery (NSS); minimally invasive surgery; lymph node sampling

Submitted Nov 21, 2019. Accepted for publication Feb 21, 2020.

doi: $10.21037 /$ tau.2020.03.03

View this article at: http://dx.doi.org/10.21037/tau.2020.03.03

\section{Introduction}

Wilms tumors (WTs) account for over 95\% of all kidney tumors in children (1), and the overall survival (OS) rate currently stands at over $90 \%$. This remarkable achievement is in many ways due to international collaboration on trials conducted by the Société Internationale d'Oncologie Pédiatrique (SIOP) and the Children's Oncology Group (COG) which supplanted the National Wilms Tumor Study Group (NWTSG) in 2002 (2). Although these two groups have a slightly different approach, they have provided a large body of evidence-based knowledge that allows for accurate risk stratification and management of WT.

In this article, we will review some of the surgical controversies in the management of WT, with special focus on the utility of minimally invasive and nephron-sparing surgical techniques.

\section{Nephron-sparing surgery in non-syndromic unilateral WT}

Traditionally, nephron sparing surgery (NSS) is indicated in children with bilateral WT, a single kidney, or an abnormal contralateral kidney, as well as in children at high risk of metachronous tumors, such as those with genetic predisposition syndromes, those who are less than a year old, and those with nephroblastomatosis (3).

Recently, the possibility that NSS should be considered in children with unilateral disease has come to the fore. As the survival rate for WT exceeds $90 \%$, reports of increased treatment-related morbidity and mortality 25 years from diagnosis have come to light (4). These morbidities include congestive heart failure due to doxorubicin exposure and lung radiation (5), and increased rates of arterial hypertension compared to healthy controls (6), amongst others. Particularly, patients with WT may be at increased risk for renal dysfunction over time, as surgery itself removes functional renal parenchyma (along with the neoplasm) and certain chemotherapeutic agents and radiotherapy are directly nephrotoxic $(6,7)$. The longterm benefits of preserving renal parenchyma need to be balanced against the possibility that NSS will adversely affect short-term outcomes, specifically with regards to overall and event-free survival (EFS) in patients with WT. 
Simply put, the ultimate goal of NSS is the preservation of renal function without compromising complete tumor resection (8). The SIOP WT-2001 protocol allows for NSS for polar or peripherally non-infiltrating tumors, which can be resected with clear margins. The report published in 2014, detailing the SIOP 2001 experience with NSS for unilateral WT for that 'NSS is not only feasible but also safe providing recommendations on suitable tumor configuration are adhered to. Although the low (4\%) relapse rate did not contribute to mortality, one must remain aware of the potential pitfalls that could threaten the patient.' (9).

The data on long-term renal function in non-syndromic unilateral WT is mixed: Cozzi et al. found $43 \%$ of adults under the age of 30 had mild renal function loss following nephrectomy for WT as children (10), whereas long-term data on patients treated in the NWTSG shows a cumulative incidence of around $0.7 \%$ only (11). Unfortunately few studies evaluate the deterioration of renal function beyond the development of end stage renal disease (ESRD) and it is possible that when more refined surrogates of renal function are investigated, the incidence of renal dysfunction will be found to be much higher (7). Similarly, the duration of available monitoring may not be long enough to detect the early development of chronic renal insufficiency with the expected decrease in nephron mass experienced with aging. The pediatric patient population is dramatically different from adults, particularly in terms of life expectancy. In adults, evidence shows that NSS for small, early-stage kidney cancers may reduce the incidence of long-term deterioration in renal function, as well as improve longterm cardiovascular and overall health $(12,13)$. Data have shown that children undergoing NSS have decreased rates of arterial hypertension compared to those undergoing $\mathrm{RN}$, with equal rates of local recurrence (14). With adequate follow-up into adulthood, the benefit of NSS in children may be even more striking.

\section{Establishing feasibility}

An attempt to determine the suitability of a tumor for NSS should be made pre-operatively, based on crosssectional imaging. That said, Davidoff et al. found that the resectability of large tumors cannot always be predicted by pre-operative imaging, and in the case of bilateral tumors, NSS should always be attempted in an effort to avoid bilateral nephrectomies. Changes induced through neoadjuvant chemotherapy may also allow tumors that initially appear non-amenable to NSS to become more favorable. In their series they successfully completed NSS in all patients in whom they set out to do so, although complications such as urine leak, urinoma, pyelonephritis and hydronephrosis may need to be accepted (15).

A report from COG (16) looked at image-based feasibility of NSS for very low-risk unilateral WT. Preoperative CT scans of a favorable sub-group (patient age younger than 2 years with unilateral stage I WT weighing $<550 \mathrm{~g}$ with no positive lymph nodes) were reviewed by a COG renal tumor committee surgeon and a COG renal tumor committee radiologist. Together they discussed the feasibility of NSS in each patient. The criteria for feasibility were (I) the ability to perform the procedure in situ, (II) the absence of tumor involving and/or directly abutting the renal hilar vessels, and (III) the ability to obtain a margin greater than $1 \mathrm{~cm}$ while preserving at least a third of the renal unit. This report found that only $8 \%$ of these favorable candidates were deemed suitable for NSS based on imaging analysis. By comparing pre-operative radiological prediction of NSS feasibility with pathological findings on resected specimens, Moorman-Voestermans and colleagues predict that pre-operative imagining studies may predict the feasibility of NSS with $80 \%$ sensitivity, $97 \%$ specificity, and $87 \%$ accuracy (17). In the adult population, scoring systems such as the RENAL nephrometry scoring system help to delineate the complexity of tumors and provide a guide regarding feasibility of NSS. However, application of this scoring system to the pediatric population found that most tumors in young children are highly complex and although this system allowed the identification of less complex tumors amenable to NSS in older children and adolescents, its utility was limited in young children with WT (18).

Cost et al. (12) describe the 'ideal candidate' for NSS as a tumor that is (I) a unifocal mass located outside of the renal hilum (and, therefore, polar and amenable to NSS) sparing a third or more of normal kidney, (II) of favorable histology, (III) shows no features of renal sinus or segmental vascular invasion, (VI) associated with no metastatic LNs, intraoperative tumor spill or gross regional disease at surgery, and $(\mathrm{V})$ has a distinct interface between tumor and renal parenchyma. This group performed a posthoc histological review of $78 \mathrm{RN}$ specimens from their institution and found that $24.4 \%$ of patients met all 5 of the above criteria. This information highlights the potential underutilization of NSS in selected cases, even without the use of neoadjuvant chemotherapy. 
Criteria for NSS, the surgical complications and oncologic outcomes of various clinical series, as well as proposed criteria for determining NSS feasibility are compared in Figure 1. Consultation and case review with a surgeon with significant experience with NSS may be beneficial to guide decision-making in children with BWT (21).

\section{Technical considerations}

The most commonly performed NSS is partial nephrectomy (PN) $(3,8)$, as this allows for resection of the tumor with a rim of normal tissue. Other options include wedge resection and enucleation (8) (see Figure 2). The traditional approach to $\mathrm{PN}$ is through a trans-abdominal incision $(3,22)$, although a retroperitoneal approach has been described (23). The kidney should be fully mobilized on the vascular and ureteric pedicle, and then walled off from the peritoneum using large abdominal swabs (3) or by surrounding the kidney with sterile plastic (22). Vessel loops should be placed around the vascular pedicle to facilitate control in case of bleeding, even if the surgeon does not intend to clamp the vessels. A bloodless field is essential to safe surgery, and this can be achieved by simply placing bulldog or other vascular clamps on the hilar vessels. Many surgeons avoid clamping off the vascular pedicle entirely however, opting instead to occlude the pedicle with a finger (22), or to digitally compress the renal parenchyma proximal to the tumor (3). The administration of intravenous Mannitol 5-7 minutes prior to vascular occlusion may prevent ischemic renal damage by decreasing intracellular edema and intrarenal resistance $(3,24)$. Simple clamping of the vessels allows the surgeon around 20-30 minutes of warm ischemic time in which to perform the resection, but cooling the kidney either with either surface ice slush or with continuous in situ cold perfusion allows for a longer time to work. Ex vivo 'back-bench' tumor resection with auto-transplantation is seldom used (3).

The procedure can also be performed with laparoscopic assistance, wherein kidney exposure and control of the renal hilum with vessel loops is obtained laparoscopically, before deciding on an optimal skin incision site, which can then also be smaller than for a purely open procedure. Lopes et al. describe a series of 6 patients operated using this technique: in this series, it was never necessary to occlude the renal pedicle, and so there was no ischemia during the procedures (25).

Gerota's fascia and the perirenal fat overlying the tumor should be left in situ, to be removed along with the tumor.
Intra-operative ultrasound (IOUS) can be used to delineate tumor margins, although a positive margin rate of up to $22.5 \%$ has been described, despite its use (24). Once the area for $\mathrm{PN}$ is identified, the parenchyma is incised sharply with a blade, or scored with diathermy, leaving a $0.5-1 \mathrm{~cm}$ margin of normal parenchyma. The $\mathrm{PN}$ is then performed, coagulating smaller vessels and ligating larger ones $(3,22)$. The collecting system should be closed with absorbable sutures. A double-J stent can be placed to assist with drainage and potentially decrease the likelihood of urine leak (22). The renal defect can be covered with perirenal fat, omentum, or oxidized cellulose (3).

Lymph nodes should be sampled thoroughly. This remains a critical technical point. Not performing lymph node sampling is one of the most common omissions during radical nephrectomy, with important therapeutic consequences. Its value is equally present in NSS.

\section{Outcomes}

Data on NSS in children with WT remains scarce, and most studies are retrospective cohorts and case series (22). From the SIOP WT 2001 study, 91/2,800 (3\%) of patients underwent NSS for unilateral WT. Compared to the patients in the same study who underwent $\mathrm{RN}$, there was no difference in the reported number of tumor capsule ruptures or lymph node ruptures. In the subgroup amongst these patients with a Stage III tumor, $87 \%$ of these were Stage III due to a positive margin. A quarter of these patients underwent conversion to $\mathrm{RN}$, and another quarter had radiotherapy only. The 5-year OS and EFS were 100\% and $94.9 \%$ respectively, which was not statistically different from the survival outcomes in the $\mathrm{RN}$ group when looking at the localized disease population only. There was a trend towards a higher number of surgical complications in the NSS group, but this did not achieve statistical significance (8).

A recent systematic review of NSS for WT found that most current studies seem to show similar rates of tumor rupture, recurrence, ESRD and survival between patients undergoing NSS and RN, but notes that differences in heterogeneity and cohort reporting makes meaningful and pooled comparisons of NSS and RN nearly impossible (26). Cost $e t a l$. identified 82 patients from the literature who underwent NSS for non-syndromic unilateral WT and compared them to a cohort from their own institution who underwent $\mathrm{RN}$, and found that once stage was controlled for, there was no statistical difference in oncological outcomes (12). 


\begin{tabular}{|c|c|c|c|c|c|}
\hline \multicolumn{6}{|l|}{ Clinical series } \\
\hline Authors & Sample & Criteria for NSS & NSS performed $\%$ & $\begin{array}{l}\text { Surgical } \\
\text { complications }\end{array}$ & Oncological outcomes \\
\hline $\begin{array}{l}\text { Horwitz et al., } \\
1996(19)\end{array}$ & $\begin{array}{l}98 \text { patients; Fourth NWTS; synchronous } \\
\text { bilateral WT }\end{array}$ & Synchronous bilateral WT & $100 \%$ & $\begin{array}{l}\text { Intestinal } \\
\text { obstruction }(7 / 94) \text {; } \\
\text { urine leak }(4 / 98)\end{array}$ & $\begin{array}{l}\text { Local recurrence: } 8 \% \text {; 4-year } \\
\text { survival: } 81.7 \%\end{array}$ \\
\hline $\begin{array}{l}\text { Moorman- } \\
\text { Voestermans et al., } \\
1998 \text { (17) }\end{array}$ & $\begin{array}{l}90 \text { patients; single centre; consecutive } \\
\text { confirmed WT cases }\end{array}$ & $\begin{array}{l}\text { Tumour in functional kidney; confined to } \\
\text { single pole; occupies }<1 / 3 \text { of kidney; no } \\
\text { vascular or collecting system invasion; clear } \\
\text { margins visible between tumour and kidney } \\
\text { or surrounding tissues; tumour resection } \\
\text { would leave at least } 60 \% \text { of residual kidney } \\
\text { in situ }\end{array}$ & $7 / 90(7.8 \%)$ & Not recorded & $\begin{array}{l}\text { Local recurrence: Nil; } 5 \text {-year } \\
\text { survival: } 5 / 7\end{array}$ \\
\hline $\begin{array}{l}\text { Davidoff et al., } \\
2008(15)\end{array}$ & $\begin{array}{l}12 \text { patients; Single centre; Synchronous } \\
\text { BWT; Pre-operative chemotherapy given } \\
\text { in all cases }\end{array}$ & $\begin{array}{l}\text { Any patient with synchronous BWT unless } \\
\text { NSS clearly contra-indicated (examples: } \\
\text { renal failure with bilateral, diffuse anaplastic } \\
\text { WT; patient requiring anticoagulation for } \\
\text { CPB for resection of atrial thrombus) }\end{array}$ & $10 / 12(83 \%)$ & $\begin{array}{l}\text { Persistent urine } \\
\text { leak }(3 / 10) ; \\
\text { urinoma }(1 / 10) \text {; } \\
\text { pyelonephritis } \\
(1 / 10) \text {; adhesive } \\
\text { SBO }(2 / 10) \text {; UPJO } \\
(1 / 10)\end{array}$ & $\begin{array}{l}\text { Residual tumour on follow-up } \\
\text { imaging: } 2 / 10 \text {; local recurrence: } \\
\text { 2/10; OS ( } 3.9 \text { years): } 83 \%\end{array}$ \\
\hline $\begin{array}{l}\text { Cost et al., } \\
2012(20)\end{array}$ & $\begin{array}{l}\text { Eighty-two patients; published cases of } \\
\text { PN for UWT identified through literature } \\
\text { search }\end{array}$ & Varied between publications & $100 \%$ & Not recorded & $\begin{array}{l}\text { Local recurrence: } 3 / 83 ; \\
\text { systemic recurrence: } 3 / 83 \\
\text { local-systemic combined } \\
\text { recurrence: } 3 / 83 \text {; OS ( } 4 \text { years) } \\
95.1 \%\end{array}$ \\
\hline \multicolumn{6}{|c|}{ Retrospective case reviews } \\
\hline Authors & Sample & \multicolumn{3}{|l|}{ Agreed criteria for NSS } & Eligible cases \\
\hline $\begin{array}{l}\text { Cost et al., } \\
2012 \text { (12) }\end{array}$ & $\begin{array}{l}\text { Seventy-eight patients; retrospective } \\
\text { specimen review; single centre; all patients } \\
\text { undergoing pre-chemotherapy and RN for } \\
\text { UWT }\end{array}$ & \multicolumn{3}{|c|}{$\begin{array}{l}\text { (I) Unifocal polar mass, sparing at least } 1 / 3 \text { of kidney; (II) Favourable histology; (III) } \\
\text { Absent renal sinus or segmental vascular invasion; (IV) No metastatic LNs, intra- } \\
\text { operative tumour spill, or gross regional disease; (V) Distinct interface between tumour } \\
\text { and renal parenchyma }\end{array}$} & $24.40 \%$ \\
\hline $\begin{array}{l}\text { Ferrer et al., } \\
2013(16)\end{array}$ & $\begin{array}{l}60 \text { patients; enrolled in COG study } \\
\text { AREN0532; }<2 \text { years old; favourable } \\
\text { histology; tumor weight }<550 \mathrm{~g} \text {; negative } \\
\text { lymph nodes }\end{array}$ & \multicolumn{3}{|c|}{$\begin{array}{l}\text { (I) Procedure could be performed in situ; (II) Absence of tumor involving/directly } \\
\text { abutting hilar vessels; (III) Able to obtain tumour margin of at least } 1 \mathrm{~cm} \text {; (VI) At least } \\
1 / 3 \text { of renal unit can be preserved }\end{array}$} & $5 / 60(8 \%)$ \\
\hline
\end{tabular}

Figure 1 Inclusion criteria, surgical complications and outcomes of NSS (12,15-17,19,20). NSS, nephron sparing surgery.

\section{Minimally invasive surgery}

Advances in technology and equipment have led to a drastic increase in the use of minimally invasive surgical (MIS) techniques across all surgical specialties, but the use of MIS in the treatment of WT is still an area of controversy and more clinical trials are needed to settle the question of its safety. Laparoscopic and robotic urologic surgery is often the technique of choice for radical nephrectomy in the adult population. Although lagging initially, the adoption of MIS in the pediatric urologic population has become increasingly common. Use of MIS for oncologic resection, however, remains low compared to non-oncologic indications. During a recent survey, only $13 \%$ of pediatric surgeons favored MIS approaches for WT, in contrast to $88 \%$ for appendectomy and $90 \%$ for fundoplication (27). Data from the National Cancer Database finds that $5 \%$ of surgeries for WT are performed using MIS (28).

Historically, recommendations for WT management called for open surgical excision only. Arguments against
MIS include the skill required for laparoscopy, decreased lymph node sampling (which affects disease staging), a perceived higher chance of tumor spillage or incomplete resection (which affects OS), and the need for laparotomy to remove the mass regardless of whether the procedure is started in an open or laparoscopic fashion.

Currently, there are no gold standard recommendations regarding MIS in WT management, and radical nephrectomy via a trans-abdominal or thoraco-abdominal incision is still recommended by many authors (21). The SIOP UMRELLA protocol does not advocate for MIS given the lack of safety reporting, however, it does provide some guidance. The protocol states that MIS for WT management is permissible for small central tumors with a rim of nonmalignant renal tissue, where adequate lymph node sampling is possible (29). Contraindications include tumor infiltration of extrarenal structures, tumor extension beyond the border of the spinal column, thrombus in the renal vein or vena cava, tumor without any response to chemotherapy, and lack of experience in laparoscopic surgery, or those patients in 

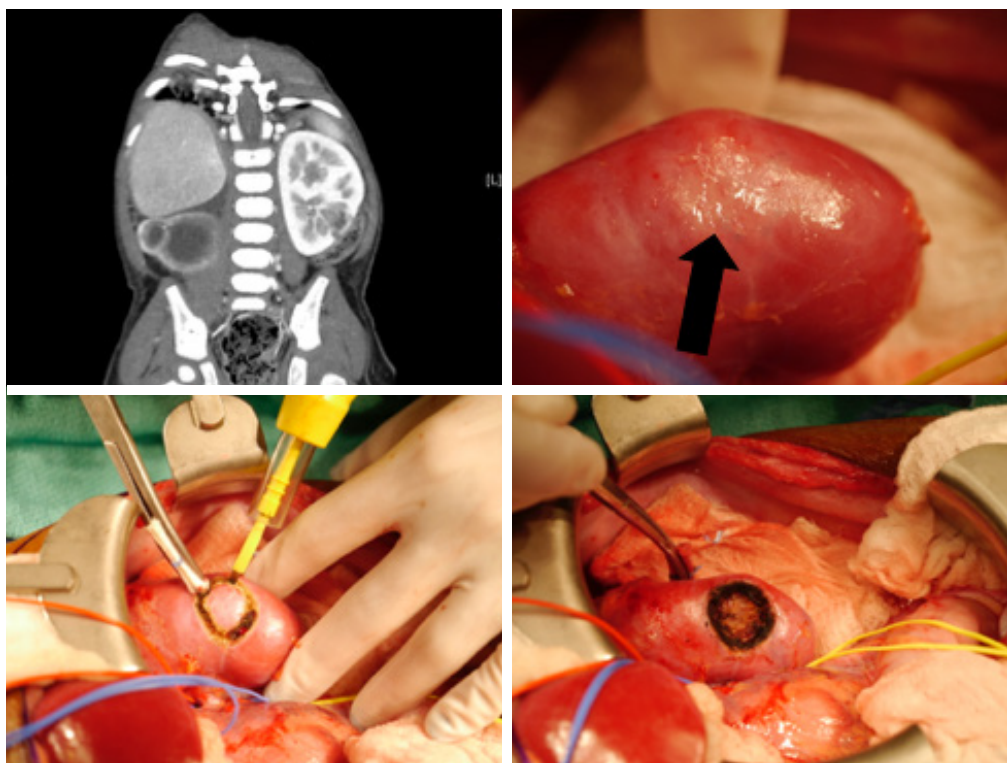

Figure 2 Bilateral Wilms tumors, with small inferior pole lesion in left kidney (indicated by black arrow). Lesion is resected after hilar control using monopolar cautery, with rim of normal renal tissue.

whom NSS cannot be performed (29). Alternative guidelines have proposed that MIS tumor resection should only be performed following induction chemotherapy and should be followed by adjuvant therapy (30). Clearly, experience plays a role. For example, Burnand et al. have reported that in experienced hands, tumors crossing the ipsilateral spinous processes may be resected safely with MIS, and adequate lymph node dissection achieved (31).

\section{Patient selection}

The most important factor agreed on by all surgeons is the importance of appropriate patient selection for MIS. Amenable patients are typically those presenting with small tumors or small tumor burden following chemotherapy, although Duarte et al. suggest that the absolute tumour size is of less importance than the dimensions of the tumor relative to the patient morphometrics (32). When comparing open $v s$. laparoscopic nephrectomy for WT, Romao et al. reported a significant difference in tumor size between the two techniques (33). Assessment of tumor size and extension is critical because it correlates with intraoperative tumor spillage (34). That said, tumors as large as $12 \mathrm{~cm}$ have been excised laparoscopically (32). Tumors that do not cross the ipsilateral vertebral border, and which allow for adequate manipulation for nodal dissection may be considered favorable for MIS (34,35). Preoperative imaging review is also critical to determine port placement, which will dictate positioning for both renal resection and lymph node sampling.

\section{Benefits}

The benefits of MIS in general are well documented. Optimal visualization allows for precise dissection. Smaller incisions and lower operative trauma allow for less pain, earlier post-operative feeding, shorter postoperative hospital stays and quicker return to regular activity (30). In patients with WT, laparoscopic surgery has been shown to have shorter hospital stay and less narcotic use compared to open techniques. The small Pfannenstiel incision generally employed during laparoscopic WT surgery has advantages over a large subcostal or transverse laparotomy incision in that it is cosmetically more acceptable and allows for more rapid post-operative recovery. Studies have shown that overall oncologic outcomes are similar (28), and risk of local recurrence following laparoscopic nephrectomy is as low as $3.8 \%$ (36), although this may be biased by the fact that patients undergoing MIS have tumors of lower stages.

\section{Potential pitfalls}

As stated previously, complete tumor resection without tumor spillage reduces the risk of local and abdominal 
recurrence. Surgeons without extensive experience with laparoscopy may be hesitant to attempt MIS for the treatment of WT due to the concern for tumor rupture in these patients. A small working space makes exploration of the renal pedicle difficult, particularly in patients with large masses or those that cross the ipsilateral spinous process. Thoroughness of lymph node sampling is another key prognostic factor in patients with WT. In comparison to open nephrectomy, laparoscopic nephrectomy had a lower yield of lymph nodes (median 2 vs. 5) (33) in multiple studies. Retrospective review of the SIOP 2001 cohort demonstrated only $63 \%$ of MIS cases for WT had any lymph node sampling at all (37).

\section{Lymph node sampling}

Lymph node sampling at the time of tumor resection is critically important (21). Lymph node stage affects pathologic staging and directs adjuvant treatment. Due

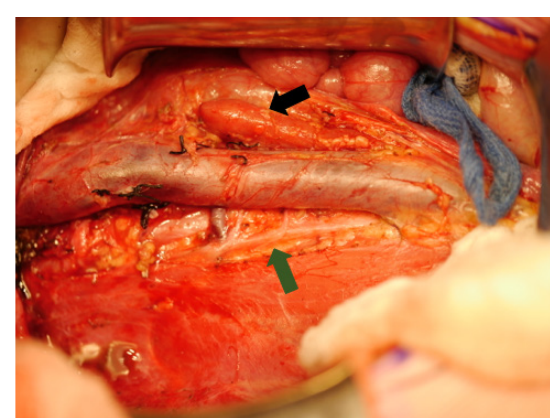

Figure 3 Inferior vena cava (IVC), which has been cleared of lymph nodes to its right (indicated by green arrow: note the visible sympathetic chain and lumbar vessels). The black arrow indicates a lymph node to the left of the IVC which was also resected. to the known discrepancy between clinical assessment and histologic findings, surgical harvest is essential, and sampling of ipsilateral nodes is the current standard of care. Presence of node positive disease within the abdomen advances pathologic staging to 3 , while node positive extraabdominal findings upgrade to stage 4 . Studies have shown that up to $41 \%$ of patients with stage 3 reach that diagnosis based on pathological lymph node positivity alone (38). LN density, which is the proportion of positive LNs relative to the total number of LNs evaluated, can also be used to predict OS, with a $\mathrm{LN}$ density of $\leq 0.38$ being a positive predictor for 5 -year survival (39). Figure 3 demonstrates the surgical bed around the IVC which in the process of being cleared of lymph nodes.

The majority of children with WT undergo cross sectional imaging, most often with CT scan. The reported correlation of CT staging and pathologic staging varies from $38 \%$ to $75 \%$. Recent arguments have centered around the lack of size criteria for nodal positivity in children. In adults, a lymph node of $>1 \mathrm{~cm}$ on CT scan is interpreted as abnormally enlarged. Lubahn et al. have established that in children with WT, a diameter of $7 \mathrm{~mm}$ or more is associated with node positivity with a negative predictive value of $89.0 \%$, a sensitivity of $70.0 \%$ and a specificity of $57.1 \%$ (40). In those patients enrolled in the SIOP trials, it has been demonstrated that radiologic changes in tumor volume following preoperative chemotherapy do not indicate lymph node status (41).

One of the most common errors during surgery is the omission of lymph node sampling. Examination of the US National Cancer Database demonstrated that $42 \%$ of patients did not have adequate nodal assessment, which is lower than NWTS/COG and SIOP studies which quoted sampling rates of $9 \%$ and $33 \%$ respectively (42). Failure to perform sampling may lead to understaging, an increased
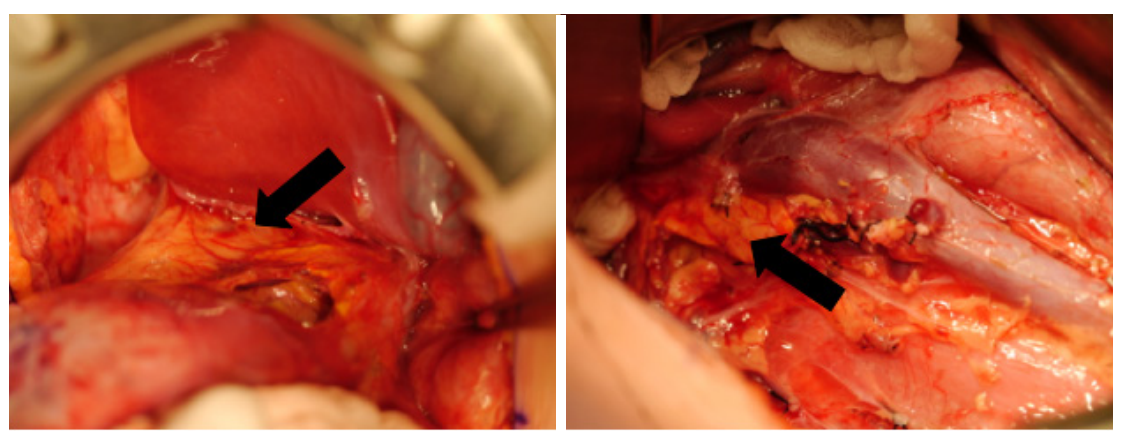

Figure 4 Black arrow indicates adrenal gland, which was separated from tumor and left in situ in this case. 
risk of recurrence and poor outcome (43). Lack of lymph node biopsy is also an independent indicator of lower OS (44). Following operative resection of the tumor, ipsilateral lymph node sampling is required. Nodal tissue from the renal hilum and the great vessels should be harvested. A key operative principal in these patients is adequacy of nodal dissection. Mathematic models have demonstrated that when histology is favorable, the adequate number of nodes required to reduce the likelihood that a positive lymph node is missed to below $10 \%$ is between 6 and 10 . Up to $30 \%$ of patients may have occult lymph node involvement when comparing lymph node yields of 2 vs. 10 nodes (45). This is confirmed by NWTS, which demonstrated that patients with positive lymph nodes increased as the yield of lymph nodes sampled increased. This correlation showed a plateau in the $\mathrm{LN}$ positivity rate at about $28 \%$ at 7 or more nodes (43).

\section{Pre-operative chemotherapy}

The decision to administer pre-nephrectomy chemotherapy in patients who are candidates for upfront nephrectomy is usually dependent on institutional protocol preference. Typically, North American groups opt for upfront nephrectomy based on the NWTS/COG protocol, whereas European groups often elect to administer pre-nephrectomy chemotherapy in accordance with SIOP protocols. It is well recognized that in environments that are dissimilar to those encountered in North America and Europe, adapted treatment protocols are required in order to offer patients the best outcome possible with the available economic and health system resources (46).

The SIOP and COG protocols regarding the administration of pre-nephrectomy chemotherapy are both safe and result in similar OS. Pre-surgical chemotherapy reduces tumor volume rendering them less likely to rupture, making this an attractive option in cases of large, operatively challenging cases of WT, and in patients where NSS or MIS are a possibility. Pre-nephrectomy chemotherapy also reduces the risk of intra-operative hemorrhage and increases the proportion of patients with low-stage tumors. Because the SIOP strategy relies on a presumptive diagnosis of WT and histological confirmation is confirmed through biopsy only in 'atypical' presentations (47), the risks of pre-nephrectomy chemotherapy include the possibility of the administration of unnecessary chemotherapy in patients with benign disease, or the administration of the incorrect chemotherapy to a tumor that is in fact not a WT. Furthermore, pre-nephrectomy chemotherapy administration may result in the loss of important staging information, with under-estimation of disease extent resulting in sub-optimal treatment (48).

As we learn more about tumor biology, the possibility of tailoring the surgical and chemotherapeutic approach to each patient's molecular characteristics may become more of a reality.

\section{Contralateral exploration}

With the availability of modern high-quality crosssectional imaging, contralateral renal exploration for patients undergoing surgery for unilateral WT is largely unnecessary. Historically, contralateral exploration was recommended when excretory urography was the only preoperative imaging modality. Now, with the advancement of CT scan and MRI, lesions measuring millimeters can be detected pre-operatively. Several studies have demonstrated high sensitivity and specificity (close to $100 \%$ ) with these modalities, with no evidence of missed disease during contralateral exploration (49). Ritchey et al. found that routine contralateral exploration may yield a small number of occult lesions not identified on pre-operative imaging, but that omission of routine contralateral exploration is unlikely to affect the outcome of any children with newly diagnosed WT, as long as they underwent CT or MRI scan prior to surgery (50).

\section{Adrenal preservation}

Little guidance is given regarding ipsilateral adrenalectomy in either the SIOP or the COG protocols. It is described historically as a standard step in RN for renal cell carcinoma (RCC) and is supported by the finding of malignant involvement of the adrenal gland in both surgical and pathological specimens. In a retrospective chart review of two groups of WT patients-one group who underwent adrenalectomy and one group where the adrenal gland was preserved-Moore et al. (51) found that the adrenal gland showed malignant invasion in only $1 / 58$ patients, and periadrenal fat involvement was noted in $3 / 58$ patients. There was no statistically significant difference in retroperitoneal recurrence between the groups. Subsequently, these findings were confirmed by COG on review of the NWTS-4 and -5 cohorts (52). Where surgically feasible, it seems that adrenalectomy can be avoided during RN $(21,52)$. Figure 4 demonstrates and adrenal gland left in situ after 
radical nephrectomy for WT.

\section{Pulmonary metastasectomy}

Approximately $10 \%$ of patients with WT present with pulmonary metastases $(\mathrm{PM})$, but they still have good OS rates (53). Traditionally, lung nodules are treated with whole-lung radiation with good disease outcomes, but this is associated with a significant increase in the incidence of pulmonary disease in the long-term (54).

Historically, PM were diagnosed and followed on chest $\mathrm{X}$-ray (CXR), but the introduction of CT scan allowed the diagnosis of lesions that were less $1 \mathrm{~cm}$ in diameter, and which could not be seen on CXR (55). The new appreciation of these undiagnosed lesions brought with it the question of how these lesions should be addressed. As many as $26 \%$ of these lesions might prove to be benign on biopsy, and might not require treatment (56), but data also demonstrates that children with CT-only lesions are at higher risk for pulmonary relapse if these lesions are not treated (57). A report from COG on the NWTS-4 and -5 found that these patients had improved 5-year EFS if they received 3 chemotherapeutic drugs rather than 2 , although the OS between the 3-and 2-drug subsets was the same. In these patients with CT-only nodules, there was no difference in EFS or OS whether or not they had lung radiation (55).

The SIOP 93-01 protocol allows for pulmonary metastasectomy in patients who do not have complete resolution (CR) of pulmonary nodules after initial chemotherapy. Patients with known PM undergo CT scan at the time of nephrectomy, and if there is CR they continue the same chemotherapy regimen for 27 weeks. If there are still residual nodules, these are resected if feasible, and the same chemotherapy regimen is given. Patients where PM are incompletely resected or resection is not feasible are given a further high-risk chemotherapy regimen. If CR is still not achieved after this, either with chemotherapy or with metastasectomy, pulmonary radiotherapy is applied to both lungs (58). In a study of 234 patients with PM, Verschuur and colleagues found that following this protocol, radiotherapy could be omitted for the majority of patients and that outcomes were still relatively good. As such, pulmonary metastasectomy is accepted as a reasonable option in patients whose PM do not clear with chemotherapy alone, as it may reduce the radiation burden in this group.

\section{Conclusions}

WT is a common pediatric tumor with generally excellent outcomes. International collaboration on the COG and SIOP databases and studies provides clinicians with a vast body of evidence-based data with which to manage these patients. Ongoing study allows for ongoing adaptations to management, with the goal of improving survival further whilst at the same time reducing treatment-associated morbidity and mortality.

In terms of surgical options, NSS in a select group of patients may help to preserve functional renal units and long-term renal function, without compromising OS and EFS. Minimally invasive surgical techniques are safe in experienced hands, and in appropriate patients. Thorough lymph node sampling is essential for disease staging and to direct adjuvant therapy. Contralateral exploration is becoming far less common in the era of highly sensitive and specific cross-sectional imaging, and data shows it is safe to preserve the ipsilateral adrenal gland where technically feasible. Pulmonary metastasectomy may provide good survival outcomes whilst obviating the need for whole-lung radiotherapy in patients with nodules that do not clear with chemotherapy.

\section{Acknowledgments}

Funding: None.

\section{Footnote}

Provenance and Peer Review: This article was commissioned by the Guest Editors (John Wiener, Jonathan Routh and Nicholas Cost) for the series "Pediatric Urologic Malignancies" published in Translational Andrology and Urology. The article was sent for external peer review organized by the Guest Editors and the editorial office.

Conflicts of Interest: All authors have completed the ICMJE uniform disclosure form (available at http://dx.doi. org/10.21037/tau-20-773). The series "Pediatric Urologic Malignancies" was commissioned by the editorial office without any funding or sponsorship. The authors have no other conflicts of interest to declare.

Ethical Statement: The authors are accountable for all aspects of the work ensuring that questions related to the accuracy 
or integrity or any part of the work are appropriately investigated and resolved.

Open Access Statement: This is an Open Access article distributed in accordance with the Creative Commons Attribution-NonCommercial-NoDerivs 4.0 International License (CC BY-NC-ND 4.0), which permits the noncommercial replication and distribution of the article with the strict proviso that no changes or edits are made and the original work is properly cited (including links to both the formal publication through the relevant DOI and the license). See: https://creativecommons.org/licenses/by-nc-nd/4.0/.

\section{References}

1. Davidoff AM, Fernandez-Pineda I. Complications in the surgical management of children with malignant solid tumors. Semin Pediatr Surg 2016;25:395-403.

2. Dome JS, Graf N, Geller JI, et al. Advances in Wilms tumor treatment and biology: Progress through international collaboration. J Clin Oncol 2015;33:2999-3007.

3. Cozzi DA, Zani A. Nephron-sparing surgery in children with primary renal tumor: Indications and results. Semin Pediatr Surg 2006;15:3-9.

4. Termuhlen AM, Tersak JM, Liu Q, et al. Twenty-five year follow-up of childhood Wilms tumor: A report from the Childhood Cancer Survivor Study. Pediatr Blood Cancer 2011;57:1210-6.

5. Green DM, Grigoriev YA, Nan B, et al. Congestive Heart Failure After Treatment for Wilms' Tumor: A Report From the National Wilms' Tumor Study Group. J Clin Oncol 2001;19:1926-34.

6. Neu MA, Russo A, Wingerter A, et al. Prospective analysis of long-term renal function in survivors of childhood Wilms tumor. Pediatr Nephrol 2017;32:1915-25.

7. Romao RL, Lorenzo AJ. Renal function in patients with Wilms tumor. Urol Oncol 2016;34:33-41.

8. Wilde JCH, Aronson DC, Sznajder B, et al. Nephron sparing surgery (NSS) for unilateral Wilms tumor (UWT): The SIOP 2001 experience. Pediatr Blood Cancer 2014;61:2175-9.

9. Wilde JCH, Laméris W, Van Hasselt EH, et al. Challenges and outcome of Wilms' tumour management in a resourceconstrained setting. Afr J Paediatr Surg 2010;7:159-62.

10. Cozzi DA, Ceccanti S, Frediani S, et al. Renal function adaptation up to the fifth decade after treatment of children with unilateral renal tumor: A crosssectional and longitudinal study. Pediatr Blood Cancer
2013;60:1534-8.

11. Lange J, Peterson SM, Takashima JR, et al. Risk factors for end stage renal disease in non-wt1-syndromic Wilms tumor. J Urol 2011;186:378-86.

12. Cost NG, Lubahn JD, Granberg CF, et al. Pathological review of Wilms tumor nephrectomy specimens and potential implications for nephron sparing surgery in Wilms tumor. J Urol 2012;188:1506-10.

13. Miller DC, Schonlau M, Litwin MS, et al. Renal and cardiovascular morbidity after partial or radical nephrectomy. Cancer 2008;112:511-20.

14. Hubertus J, Günther B, Becker K, et al. Development of Hypertension is Less Frequent after Bilateral Nephron Sparing Surgery for Bilateral Wilms Tumor in a LongTerm Survey. J Urol 2015;193:262-6.

15. Davidoff AM, Giel DW, Jones DP, et al. The feasibility and outcome of nephron-sparing surgery for children with bilateral Wilms tumor: The St. Jude Children's Research Hospital experience: 1999-2006. Cancer 2008;112:2060-70.

16. Ferrer FA, Rosen N, Herbst K, et al. Image based feasibility of renal sparing surgery for very low risk unilateral Wilms tumors: A report from the children's oncology group. J Urol 2013;190:1846-51.

17. Moorman-Voestermans CGM, Aronson DC, Staalman $\mathrm{CR}$, et al. Is partial nephrectomy appropriate treatment for unilateral Wilms' tumor? J Pediatr Surg 1998;33:165-70.

18. Cost NG, DeFoor WR, Crotty EJ, et al. The initial experience with RENAL nephrometry in children, adolescents, and young adults with renal tumors. Pediatr Blood Cancer 2014;61:1434-9.

19. Horwitz JR, Ritchey ML, Moksness J, et al. Renal salvage procedures in patients with synchronous bilateral Wilms' tumors: a report from the National Wilms' Tumor Study Group. J Pediatr Surg 1996;31:1020-5.

20. Cost NG, Lubahn JD, Granberg CF, et al. Oncologic outcomes of partial versus radical nephrectomy for unilateral Wilms tumor. Pediatr Blood Cancer 2012;58:898-904.

21. Aldrink JH, Heaton TE, Dasgupta R, et al. Update on Wilms tumor. J Pediatr Surg 2019;54:390-7.

22. Millar AJW, Cox S, Davidson A. Management of bilateral Wilms tumours. Pediatr Surg Int 2017;33:737-45.

23. Lim II, Honeyman JN, Fialkowski EA, et al. Experience with Retroperitoneal Partial Nephrectomy in Bilateral Wilms Tumor. Eur J Pediatr Surg 2015;25:113-7.

24. Aldrink JH, Cost NG, McLeod DJ, et al. Technical considerations for nephron-sparing surgery in children: what is needed to preserve renal units? J Surg Res 
2018;232:614-20.

25. Lopes RI, Ming J, Koyle MA, et al. "Zero-Ischemia" Laparoscopic-assisted Partial Nephrectomy for the Management of Selected Children With Wilms Tumor Following Neoadjuvant Chemotherapy. Urology 2017;100:103-10.

26. Vanden Berg RN, Bierman EN, Noord MV, et al. Nephron-sparing surgery for Wilms tumor: A systematic review. Urol Oncol 2016;34:24-32.

27. Jones VS, Cohen RC. Two decades of minimally invasive pediatric surgery-taking stock. J Pediatr Surg 2008;43:1653-9.

28. Ezekian B, Englum BR, Gulack BC, et al. Comparing oncologic outcomes after minimally invasive and open surgery for pediatric neuroblastoma and Wilms tumor. Pediatr Blood Cancer 2018;65:e26755.

29. van den Heuvel-Eibrink MM, Hol JA, Pritchard-Jones K, et al. Rationale for the treatment of Wilms tumour in the UMBRELLA SIOP-RTSG 2016 protocol. Nat Rev Urol 2017;14:743-52.

30. Galazka P, Czyzewski K, Marjanska A, et al. Minimally Invasive Surgery in Pediatric Oncology: Proposal of Guidelines. Anticancer Res 2019;39:5853-9.

31. Burnand K, Roberts A, Bouty A, et al. Laparoscopic nephrectomy for Wilms' tumor: Can we expand on the current SIOP criteria? J Pediatr Urol 2018;14:253.e1253.e8.

32. Duarte RJ, Cristofani LM, Odone Filho V, et al. Videolaparoscopic radical nephrectomy after chemotherapy in the treatment of Wilms' tumor: Long-term results of a pioneer group. J Pediatr Urol 2017;13:50.e1-50.e5.

33. Romao RLP, Weber B, Gerstle JT, et al. Comparison between laparoscopic and open radical nephrectomy for the treatment of primary renal tumors in children: Singlecenter experience over a 5-year period. J Pediatr Urol 2014;10:488-94.

34. Schmidt A, Warmann SW, Urla C, et al. Patient selection and technical aspects for laparoscopic nephrectomy in Wilms tumor. Surg Oncol 2019;29:14-9.

35. Flores P, Cadario M, Lenz Y, et al. Laparoscopic total nephrectomy for Wilms tumor: Towards new standards of care. J Pediatr Urol 2018;14:388-93.

36. Bouty A, Burnand K, Nightingale $M$, et al. What is the risk of local recurrence after laparoscopic transperitoneal radical nephrectomy in children with Wilms tumours? Analysis of a local series and review of the literature. J
Pediatr Urol 2018;14:327.e1-327.e7.

37. Warmann SW, Godzinski J, Van Tinteren H, et al. Minimally invasive nephrectomy for Wilms tumors in children - Data from SIOP 2001. J Pediatr Surg 2014;49:1544-8.

38. Ehrlich PF, Ritchey ML, Hamilton TE, et al. Quality assessment for Wilms' tumor: a report from the National Wilms' Tumor Study-5. J Pediatr Surg 2005;40:208-12; discussion 212-3.

39. Saltzman AF, Carrasco A, Amini A, et al. Patterns of lymph node sampling and the impact of lymph node density in favorable histology Wilms tumor: An analysis of the national cancer database. J Pediatr Urol 2018;14:161.e1-161.e8.

40. Lubahn JD, Cost NG, Kwon J, et al. Correlation Between Preoperative Staging Computerized Tomography and Pathological Findings After Nodal Sampling in Children with Wilms Tumor. J Urol 2012;188:1500-4.

41. Godzinski J, van Tinteren H, de Kraker J, et al. Nephroblastoma: does the decrease in tumor volume under preoperative chemotherapy predict the lymph nodes status at surgery? Pediatr Blood Cancer 2011;57:1266-9.

42. Raval MV, Bilimoria KY, Bentrem DJ, et al. Nodal Evaluation in Wilms' Tumors. Ann Surg 2010;251:559-65.

43. Kieran K, Ehrlich PF. Current surgical standards of care in Wilms tumor. Urol Oncol 2016;34:13-23.

44. Zhuge Y, Cheung MC, Yang R, et al. Improved Survival with Lymph Node Sampling in Wilms Tumor. J Surg Res 2011;167:e199-203.

45. Saltzman AF, Smith DE, Gao D, et al. How Many Lymph Nodes Are Enough? Assessing the Adequacy of Lymph Node Yield for Staging in Favorable Histology Wilms Tumor. J Pediatr Surg 2019;54:2331-5.

46. Paintsil V, David H, Kambugu J, et al. The Collaborative Wilms Tumour Africa Project; Baseline evaluation of Wilms tumour treatment and outcome in eight institutes in sub-Saharan Africa. Eur J Cancer 2015;51:84-91.

47. de la Monneraye Y, Michon J, Pacquement H, et al. Indications and results of diagnostic biopsy in pediatric renal tumors: A retrospective analysis of 317 patients with critical review of SIOP guidelines. Pediatr Blood Cancer 2019;66:e27641.

48. Green DM. The evolution of treatment for Wilms tumor. J Pediatr Surg 2013;48:14-9.

49. Kessler O, Franco I, Jayabose S, et al. Is Contralateral Exploration of the Kidney Necessary in Patients With Wilms Tumor? J Urol 1996;156:693-5.

50. Ritchey ML, Shamberger RC, Hamilton T, et al. Fate of 
Bilateral renal lesions missed on preoperative imaging: a report from the National Wilms Tumor Study Group. J Urol 2005;174:1519-21.

51. Moore K, Leslie B, Salle JLP, et al. Can we spare removing the adrenal gland at radical nephrectomy in children with Wilms tumor? J Urol 2010;184:1638-43.

52. Kieran K, Anderson JR, Dome JS, et al. Is adrenalectomy necessary during unilateral nephrectomy for Wilms Tumor? A report from the Children's Oncology Group. J Pediatr Surg 2013;48:1598-603.

53. Heaton TE, Davidoff AM. Surgical treatment of pulmonary metastases in pediatric solid tumors. Semin Pediatr Surg 2016;25:311-7.

54. Green DM, Lange JM, Qu A, et al. Pulmonary disease after treatment for Wilms tumor: A report from the national Wilms tumor long-term follow-up study. Pediatr Blood Cancer 2013;60:1721-6.

55. Grundy PE, Green DM, Dirks AC, et al. Clinical

Cite this article as: Milford K, DeCotiis K, Lorenzo A. Wilms tumor: a review of current surgical controversies. Transl Androl Urol 2020;9(5):2382-2392. doi:10.21037/tau.2020.03.03 significance of pulmonary nodules detected by CT and Not CXR in patients treated for favorable histology Wilms tumor on national Wilms tumor studies-4 and -5: A report from the Children's Oncology Group. Pediatr Blood Cancer 2012;59:631-5.

56. Ehrlich PF, Hamilton TE, Grundy P, et al. The value of surgery in directing therapy for patients with Wilms' tumor with pulmonary disease. A report from the National Wilms' Tumor Study Group (National Wilms' Tumor Study 5). J Pediatr Surg 2006;41:162-7.

57. Wilimas JA, Douglass EC, Magill HL, et al. Significance of pulmonary computed tomography at diagnosis in Wilms' tumor. J Clin Oncol 1988;6:1144-6.

58. Verschuur A, Van Tinteren H, Graf N, et al. Treatment of pulmonary metastases in children with stage IV nephroblastoma with risk-based use of pulmonary radiotherapy. J Clin Oncol 2012;30:3533-9. 